\title{
"Why be normal?": Language and identity practices in a community of nerd girls
}

\author{
M A R Y B U C H O LT Z \\ Department of English \\ Texas A\&M University \\ College Station, TX 77843-4227 \\ bucholtz@tamu.edu
}

\section{A B S T R AC T}

The introduction of practice theory into sociolinguistics is an important recent development in the field. The community of practice provides a useful alternative to the speech-community model, which has limitations for language and gender researchers in particular. As an ethnographic, activitybased approach, the community of practice is of special value to researchers in language and gender because of its compatibility with current theories of identity. An extension of the community of practice allows identities to be explained as the result of positive and negative identity practices rather than as fixed social categories, as in the speech-community model. The framework is used here to analyze the linguistic practices associated with an unexamined social identity, the nerd, and to illustrate how members of a local community of female nerds at a US high school negotiate gender and other aspects of their identities through practice. (Community of practice, gender, discourse analysis, identity, social construction, social practice, speech community, adolescents, nerds)*

In sociolinguistics, social theory is rooted in the concept of the speech community. As a language-based unit of social analysis, the speech community has allowed sociolinguists to demonstrate that many linguistic phenomena previously relegated to the realm of free variation are in fact socially structured. Thus Labov 1966 showed that the linguistic heterogeneity of New York City can be quantitatively analyzed as the patterning of a single speech community, despite differences in New Yorkers' language use based on sociological variables such as age, social class, and gender.

Nonetheless, because the concept of speech community is indigenous to sociolinguistics, it is not connected to any larger social theory. This theoretical isolation, along with the fact that the speech community defines the social world in strictly (socio) linguistic terms, has meant that sociolinguistic theory has largely stood apart from theoretical advances in related disciplines. Meanwhile, within sociolinguistics, the concept of the speech community has been hotly contested

(C) 1999 Cambridge University Press 0047-4045/99 \$9.50 
and continually revised as researchers have uncovered the limitations of previous definitions.

The speech community presents special difficulties for researchers in the sociolinguistic subfield of language and gender. The disciplinary autonomy of theory based on the speech community is unproblematic for traditional sociolinguistic research, which uses social information to account for linguistic phenomena such as sound change. But when sociolinguists reverse the direction of analysis - asking instead how linguistic data can illuminate the social world, as language and gender researchers seek to do - then connections to social theory beyond linguistics become imperative. Moreover, the speech community model, which was designed to analyze sociolinguistic phenomena at a macro level, is often inappropriate and inadequate for the kinds of questions currently being asked in language and gender scholarship. Central among these is the question of identity: How do speakers use language to project their identities as gendered beings? And how are gender identities interwoven with other social parameters?

This article draws on a theory of community and identity that avoids the problems associated with the speech community model. The new framework, the community of practice, emerges from PRACTICE THEORY, an approach that has currency in such disciplines as sociology, anthropology, and education. The connections of the community of practice to these recent developments in other fields allow sociolinguists to offer more fully theorized social explanations than were possible with the earlier model. In addition, the community of practice overcomes many of the faults that sociolinguists have found with the speech community, and it therefore has wide applicability to the field's central questions. The theory's broad range of use is especially evident in language and gender studies because, unlike the speech community, the community of practice was introduced into sociolinguistics specifically to address issues of gender.

In this article, I build on the theory of the community of practice to develop its potential as an analytic tool for the sociolinguistic investigation of gendered identities. The framework is applied to a social identity, that of the nerd, which has remained out of bounds in traditional sociolinguistic research based on the speech community. This identity is analyzed within the community of practice framework because only this concept permits us to draw on the linguistic and social information necessary to understand the production of nerd identity. I argue that nerd identity, contrary to popular perceptions, is not a stigma imposed by others, but a purposefully chosen alternative to mainstream gender identities which is achieved and maintained through language and other social practices.

LANGUAGE AND PRACTICE THEORY

The idea that the social world is best viewed as a set of practices is not new. Praxis is a foundational concept of Marxism, and more recently Giddens 1979 
has offered a practice-based account as a way out of the impasse created by social structure, on the one hand, and personal agency, on the other. Given the focus of practice theory on enduring social activity, it was perhaps inevitable that it should soon come to view language as a central object of social analysis. Outside linguistics, this perspective has been most fully articulated by the French sociologists Pierre Bourdieu (1978, 1991) and Michel de Certeau (1984). Both Bourdieu and Certeau understand language in relation to other social practices, and both scholars view language as a social phenomenon, rather than merely as an abstract formal system. As a consequence, they explicitly align their work with the sociolinguistic enterprise, broadly conceived; the litany of familiar names they invoke includes Joshua Fishman, Erving Goffman, William Labov, and Emanuel Schegloff.

For Bourdieu, the starting point of practice is HABITUS, the set of dispositions to act (e.g. speak, walk, read, or eat) in particular ways which are inculcated in each individual through implicit and explicit socialization. These dispositions are linked to particular social dimensions such as class and gender. Habitus is also tied to the body via HEXIS, the individual's habitual and socially meaningful embodied stances and gestures, and through other aspects of physical self-presentation. Language is merely one practice in which habitus is embedded, and through which the individual becomes socially locatable to observers. Thus non-linguistic social practices and language should be approached in analogous ways. As Bourdieu observes (1991:89),

Not only are linguistic features never clearly separated from the speaker's whole set of social properties (bodily hexis, physiognomy, cosmetics, clothing), but phonological (or lexical, or any other) features are never clearly separated from other levels of language; and the judgement which classifies a speech form as "popular" or a person as "vulgar" is based, like all practical predication, on sets of indices which never impinge on consciousness in that form.

Bourdieu here offers two important methodological insights to sociolinguists: first, that non-linguistic practices may carry important linguistic information (and vice versa); and second, that a complete sociolinguistic analysis must examine multiple levels of language simultaneously. Yet, as a theorist, Bourdieu is less useful to sociolinguists, and especially to language and gender scholars. His insistence on the unconsciousness of practice reflects a general attenuation of agency within his theory. Although speakers are not bound by their habitus, which is inflected by the particular context in which it occurs, the tendency is to act in accordance with what has been naturalized as appropriate. Bourdieu sees the individual, then, more as a product of social structure than as a free agent. Practice at the local level - especially linguistic practice, which is embedded in the class habitus of the standard and the non-standard - is primarily in the business of reproducing existing social arrangements. 
For Certeau, by contrast, the individual is much more agentive, because the focus of investigation is subversion as well as reproduction of the social order. But like Bourdieu, Certeau finds inspiration for his project in linguistics:

Our investigation ... can use as its theoretical model the CONSTRUCTION of individual sentences with an ESTABLISHED vocabulary and syntax. In linguistics, "performance" and "competence" are different: the act of speaking (with all the enunciative strategies that implies) is not reducible to a knowledge of the language. By adopting the point of view of enunciation - which is the subject of our study - we privilege the act of speaking; according to that point of view, speaking operates within the field of a linguistic system; it effects an appropriation, or reappropriation, of language by its speakers; it establishes a PRESENT relative to a time and place; and it posits a CONTRACT WITH THE OTHER (the interlocutor) in a network of places and relations. These four characteristics of the speech act can be found in many other practices (walking, cooking, etc.). (1984:xiii; original emphasis)

Certeau here makes the link between language and other social practices even more explicit than did Bourdieu before him. Certeau sees all social practices, both linguistic and non-linguistic, as similar in their social effects. But where Bourdieu considers practice to be a reproduction of social structure, Certeau views it as an appropriation, an act of agency. The point, then, is to understand how culturally shared resources (such as language) are made to serve the specific social needs of individuals. These needs may enforce the social status quo, but they may just as easily challenge or revise it.

A third theory of practice has been developed within anthropology by Ortner 1996, who criticizes earlier scholarship on the grounds that it fails to take seriously the practices of women. Making the female agent central in the project of practice theory, Ortner constructs a framework that has room for both structure and agency. Although language is not a guiding concept in Ortner's work as it is for Bourdieu and Certeau, she views structure itself as textual in nature - the "field of a linguistic system", in Certeau's words - within which an individual act of speaking operates. Thus a complete analysis of gender, and especially of language and gender, cannot focus on texts alone. As Ortner argues (1996:2),

Studies of the ways in which some set of "texts" - media productions, literary creations, medical writings, religious discourses, and so on - "constructs" categories, identities, or subject positions, are incomplete and misleading unless they ask to what degree those texts successfully impose themselves on real people (and which people) in real time. Similarly, studies of the ways in which people resist, negotiate, or appropriate some feature of their world are also inadequate and misleading without careful analysis of the cultural meanings and structural arrangements that construct and constrain their "agency", and that limit the transformative potential of all such intentionalized activity. 
The possibility - and the reality - of such unified analyses within language and gender studies is offered by the community of practice framework. More than any previous approach in sociolinguistics, the community of practice allows researchers to examine, in a theoretically adequate way, both the actions of individuals and the structures that are thereby produced and reproduced, resisted and subverted.

GENDER, THE SPEECH COMMUNIT Y,

AND THE COMMUNITY OF PRACTICE

Ortner's introduction of a feminist perspective was a relatively late development in practice theory in anthropology and sociology. Likewise, the theory of the community of practice, which emerged from education (Lave 1988, Lave \& Wenger 1991, Wenger 1998), was not applied to gender until it was imported into linguistics by Eckert \& McConnell-Ginet in a highly influential survey article (1992). As an alternative to the speech community - a central analytic tool of sociolinguistics - the community of practice requires language and gender scholars to rethink traditional notions of community, identity, and gender. However, Eckert \& McConnell-Ginet do not offer an explicit critique of the speech community; although that concept has been widely debated (see Hudson 1980, Williams 1992), its particular limitations for language and gender research have not been systematically addressed. I suggest six ways in which the speech community has been an inadequate model for work on language and gender:

(a) Its tendency to take language as central.

(b) Its emphasis on consensus as the organizing principle of community.

(c) Its preference for studying central members of the community over those at the margins.

(d) Its focus on the group at the expense of individuals.

(e) Its view of identity as a set of static categories.

(f) Its valorization of researchers' interpretations over participants' own understandings of their practices.

\section{Language vs. social practice}

The speech community has been defined in many ways, but every definition posits language as a primary criterion of community. What is taken as shared may be the linguistic system (Bloomfield 1933:42-56); or shared linguistic norms (Labov 1972, Guy 1988); the pattern of variation (Milroy 1992); or only a set of sociolinguistic norms (Romaine 1982). The emphasis may be less on the linguistic system, and more on shared interactional settings and norms (Hymes 1974, Dorian 1982, Silverstein 1996). But in every case, the focus remains on language. Even many scholars who advocate a more interactional approach understand INTERACTION to be a preeminently linguistic concept. Other forms of mutual engagement - that is, all non-linguistic aspects of social activity - are marginalized or ignored. 
By recognizing practice - the social projects of participants - as the motivating context for linguistic interaction, the theory of the community of practice makes activity much more central to sociolinguistic analysis. Just as importantly, whereas the speech community model understands language as fundamentally disembodied - as detachable from the physicality of speakers - the community of practice quite literally reincorporates language into the physical self. In this regard, it echoes Bourdieu's concept of hexis - a crucial connection for feminist researchers, for whom the specificity of the gendered body is a theoretical starting point.

\section{Consensus vs. conflict}

Another aspect of the traditional model that has received a great deal of criticism is the idea that the speech community is constituted around shared sociolinguistic norms. This definition was first proposed by Labov 1972, and was taken up by many subsequent researchers. The postulate that speakers agree on and uphold certain linguistic forms as normative, regardless of differences in social background, assumes a consensus model of society that is at odds with a long-standing tradition of social theory. Several sociolinguists have critiqued the Labovian definition of the speech community on these grounds (e.g. Rickford 1986, Milroy 1992). Moreover, the invocation of "norms" obscures the fact that these are successfully imposed ideologies favoring the interests of the powerful (Bourdieu 1991). This arrangement has long been recognized by scholars of language and gender who have worked to combat views of women's language as deficient in comparison to men's (see Cameron 1992:42 ff.)

\section{Central vs. marginal members}

The language of norms also presumes that some members of the speech community are central and others are marginal, and that it is the central members who are of interest. To be sure, the structured heterogeneity of the speech community improves on earlier models by recognizing the existence and systematicity of heterogeneity; however, speakers who do not share the same norms (for example, because they are recent immigrants or transplants from other regions) are excluded from the community. ${ }^{1}$ Thus, despite the model's emphasis on heterogeneity, the focus is in fact on what speakers share. Marginal members rarely enter the analysis, and when they do, they remain at the margins; their linguistic practices are used primarily to demonstrate how they fall short of central membership. Language and gender researchers are acutely aware of the problems with this approach. Because women may be defined, implicitly or explicitly, as marginal to the vernacular speech community, they may be underrepresented or simply misrepresented (cf. Morgan 1999). Speakers whose identities differ from those of the wider community - especially those whose gender identities do not conform to community norms - are likewise omitted or obscured in research within this paradigm. 
The expectation of consensus in speech community norms also requires that the system be closed to outside influence. The possibility of interaction between speech communities is not important in the model. ${ }^{2}$ Hence researchers seek sameness, not difference; difference (e.g. in language use) is contained by interpreting it as sameness at an underlying level (e.g. in shared sociolinguistic norms). With this emphasis on analysis of the group as an autonomous system, phenomena resulting from linguistic and cultural contact (Pratt 1987) may be overlooked. For example, the focus on the internal workings of the speech community does not accommodate investigations of gendered interaction across cultural groups.

\section{Groups vs. individuals}

Related to the problem of homogeneity in the speech community model is its privileging of the group over the individual as the unit of analysis. In such an approach, the role of the individual is merely to instantiate the practices of the group. Individual actions result less from choice and agency than from a social order that impinges on individuals from above. The traditional model's strong preference for structure over agency means that individual variation, or style, is interpreted as the mechanical outcome of structural forces such as situational norms. A more agentive view locates style in personal choices concerning selfpresentation (Johnstone 1995, 1996, Johnstone \& Bean 1997). This perspective, which also admits structural constraints on the individual, is well suited for gender studies, given the field's longtime recognition that individuals make purposeful choices in the face of the limitations imposed on them by social structures. As Ortner notes above, one of the benefits of practice theory is its ability to cope with both aspects of women's (and men's) lives.

\section{Identity categories vs. identity practices}

The structural perspective is a static perspective, one in which the social order remains largely unaltered. Changes in the practices of its inhabitants have the effect of keeping the system in equilibrium. Nowhere is this more evident than in the speech community model's implicit theory of identity: Individuals are viewed as occupying particular social identities throughout their lives by virtue of their position in the social structure. Such an analysis is particularly problematic for researchers of language and gender. The concept of identity is central to genderoriented research, but the version offered by the speech community framework contradicts basic insights of recent feminist theory. Contemporary feminists view identities as fluid, not frozen; they note that, although identities link individuals to particular social groups, such links are not predetermined. Instead, identities emerge in practice, through the combined effects of structure and agency. Individuals engage in multiple identity practices simultaneously, and they are able to move from one identity to another. This process is not entirely unconstrained; speakers may end up reproducing hegemonic identities more often than resisting 
them, as suggested by Holmes 1997. It is also important, however, to call attention to the previously unacknowledged flexibility of identity formation.

\section{Top-down vs. bottom-up}

For the specificity of identity to become visible, it must be examined from the point of view of the individuals who enact it. Such a vantage point is not available within the speech community model, which privileges the analyst's interpretations over those of participants. Indeed, the speech community itself is an analytic construct which may fail to correspond to its putative members' own perceptions. Nonetheless, many analyses are carried out under the belief that the linguist has access to elements of speakers' reality that are not available to the speakers themselves.

An alternative to this top-down paradigm is ETHNOGRAPHY, an approach that is participant- rather than analyst-driven. Where the speech community framework is skeptical of speakers' perspectives on their own practices, ethnography makes local interpretations central to the analysis. Gender does not have the same meanings across space and time, but is instead a local production, realized differently by different members of a community; thus an ethnographic orientation yields particularly fruitful results for language and gender research.

NERDS, GENDER, AND THE COMMUNITY OF PRACTICE

The inadequacies of the speech community model for scholars of language and gender are overcome in the theory of the community of practice as articulated by Eckert \& McConnell-Ginet 1992, $1995 .^{3}$ Rather than investing language with a special analytic status, the community of practice framework considers language as one of many social practices in which participants engage. By defining the community as a group of people oriented to the same practice, though not necessarily in the same way, the community of practice model treats difference and conflict, not uniformity and consensus, as the ordinary state of affairs. The inherent heterogeneity of the community of practice also brings marginal members to the forefront of analysis. One reason for this shift to the margins is that some peripheral members are recognized as novices, as in Lave \& Wenger's original formulation (1991). More importantly, however, the community of practice, unlike the speech community, may be constituted around any social or linguistic practice, no matter how marginal from the perspective of the traditional speech community. Likewise, by focusing on individuals as well as groups, the theory of the community of practice integrates structure with agency. And because identities are rooted in actions rather than categories, the community of practice model can capture the multiplicity of identities at work in specific speech situations more fully than is possible within the speech community framework. Such nuanced description is also facilitated by Eckert \& McConnell-Ginet's intrinsically ethnographic approach to language and gender research. The remainder of this article draws on the above characteristics of the community of practice to dem- 
onstrate the theory's utility in the investigation of an understudied social identity as it emerges locally in a high-school setting.

Eckert 1989a offers an account of the social organization of a typical suburban US high school. She found that students' social worlds and identities were defined by two polar opposites: the Jocks (overachieving students who oriented to middle-class values) and the Burnouts (underachieving students who were bound for work, rather than college, at the end of their high-school careers). Yet the dichotomy that separated these students also united them in what can be understood as a single community of practice, since the ultimate goal of members of both groups was to be cooL. The difference lay in how each group defined coolness.

Not all high-school students, however, share the Jocks' and Burnouts' preoccupation with coolness. A third group, the nerds, defines itself largely in opposition to "cool" students - whether Jocks, Burnouts, or any other social identity. Nerds stand as the antithesis of all these groups, a situation that Eckert succinctly captures in her observation, "If a Jock is the opposite of a Burnout, a nerd is the opposite of both" (1989a:48). But despite the structural significance of the nerd in the organization of youth identities, few researchers have examined its implications, and those who have tried have fallen far short of the mark in their analyses. Thus the sociologist David Kinney, in a rare study of nerds (1993), argues that, in order to succeed socially, nerds must undergo a process of "recovery of identity" that involves broadening one's friendship network, participating in extracurricular activities, and heterosexual dating: In short, they must become Jocks. Another scholarly treatment (Tolone \& Tieman 1990) investigates the drug use of nerds in an article subtitled "Are loners deviant?" - in other words, are nerds really Burnouts?

What both studies overlook is that being a nerd is not about being a failed Burnout or an inadequate Jock. It is about rejecting both Jockness and Burnoutness, and all the other forms of coolness that youth identities take. Although previous researchers maintain that nerd identity is invalid or deficient, in fact nerds, like Jocks and Burnouts, to a great extent consciously choose and display their identities through language and other social practices. And where other scholars tend to equate nerdiness with social death, I propose that nerds in US high schools are not socially isolated misfits, but competent members of a distinctive and oppositionally defined community of practice. Nerdiness is an especially valuable resource for girls in the gendered world of the US high school.

Elsewhere (Bucholtz 1998) I describe the social identity of the nerd and detail the phonological, syntactic, lexical, and discourse practices through which nerd identity is linguistically indexed. Here I propose a framework for the classification of such practices. These linguistic indices are of two kinds: NEGATIVE IDENTITY PRACTICES are those that individuals employ to distance themselves from a rejected identity, while POSITIVE IDENTITY PRACTICES are those in which individuals engage in order actively to construct a chosen identity. In other words, negative identity practices define what their users are NOT, and hence emphasize 
TABLE 1. Linguistic identity practices of nerds at Bay City High School.

\begin{tabular}{|c|c|c|}
\hline Linguistic Level & Negative Identity Practices & Positive Identity Practices \\
\hline Phonology & $\begin{array}{l}\text { Lesser fronting of (uw) and } \\
\qquad(\mathrm{ow})^{a}\end{array}$ & \\
\hline Phonology & $\begin{array}{l}\text { Resistance to colloquial } \\
\text { phonological processes } \\
\text { such as vowel reduction, } \\
\text { consonant-cluster simplifi- } \\
\text { cation, and contraction }\end{array}$ & $\begin{array}{l}\text { Employment of superstan- } \\
\text { dard and hypercorrect } \\
\text { phonological forms (e.g. } \\
\text { spelling pronunciations) }\end{array}$ \\
\hline Syntax & $\begin{array}{l}\text { Avoidance of nonstandard } \\
\text { syntactic forms }\end{array}$ & $\begin{array}{l}\text { Adherence to standard and } \\
\text { superstandard syntactic } \\
\text { forms }\end{array}$ \\
\hline Lexicon & Avoidance of current slang & $\begin{array}{l}\text { Employment of lexical items } \\
\text { associated with the formal } \\
\text { register (e.g. Greco- } \\
\text { Latinate forms) }\end{array}$ \\
\hline Discourse & & $\begin{array}{l}\text { Orientation to language form } \\
\text { (e.g. punning, parody, } \\
\text { word coinage) }\end{array}$ \\
\hline
\end{tabular}

${ }^{a}$ In Bucholtz 1998 I offer a fuller discussion of the phonological and syntactic patterns of nerds. The present article focuses primarily on lexicon and on discursive identity practices. The variables (uw) and (ow) are part of a vowel shift that is characteristic of California teenagers (Hinton et al. 1987, Luthin 1987). It is stereotypically associated with trendy and cool youth identities.

identity as an intergroup phenomenon; positive identity practices define what their users ARE, and thus emphasize the intragroup aspects of social identity. The linguistic identity practices of nerds in the present study are shown in Table 1.

The negative identity practices listed here work to disassociate nerds from non-nerds, and especially from cool teenagers. Each of these practices, which mark nerdy teenagers as avowedly uncool, constitutes a refusal to engage in the pursuit of coolness that consumes other students. Meanwhile, all the positive identity practices listed contribute to the speaker's construction of an intelligent self - a primary value of nerd identity. These linguistic practices also have nonlinguistic counterparts in positive and negative identity practices of other kinds (see below).

But linguistic practices can often reveal important social information that is not available from the examination of other community practices alone. For example, Eckert \& McConnell-Ginet 1995 apply the theory of the community of practice to Eckert's study of Jocks and Burnouts. Linguistic analysis revealed that the two groups were participating at different rates in the Northern Cities Vowel Shift, with the most innovative vowels being those used by the "BurnedOut Burnout girls", the most extreme adherents to this social identity. Eckert \& 
McConnell-Ginet's finding runs counter to the sociolinguistic tenet that "in stable variables, women use fewer non-standard variants than men of the same social class and age under the same circumstances" (Chambers 1995:112). ${ }^{4}$ The researchers argue that the vowels employed by the Burned-Out Burnout girls are resources through which they construct their identities as tough and streetwise; unlike the boys, who can display their toughness through physical confrontations, female Burnouts must index their identities semiotically, because fighting is viewed as inappropriate for girls. Thus Burnout girls and boys share an orientation toward toughness in their community of practice, but the practice of toughness is achieved in different ways by each gender. By viewing language as equivalent to other social practices like fighting, Eckert \& McConnell-Ginet are able to explain the ethnographic meaning of the Burnout girls' vowel systems, and to show how, as symbolic capital (Bourdieu 1978), language can acquire the empowering authority of physical force itself.

Nerds, of course, attain empowerment in very different ways than either Burnouts or Jocks. One of the primary ways they differ from these other, more trendconscious groups is through the high value they place on individuality. Compared to both Jocks and Burnouts - who must toe the subcultural line in dress, language, friendship choices, and other social practices - nerds are somewhat less constrained by peer-group sanctions.

For girls, nerd identity also offers an alternative to the pressures of hegemonic femininity - an ideological construct that is at best incompatible with, and at worst hostile to, female intellectual ability. Nerd girls' conscious opposition to this ideology is evident in every aspect of their lives, from language to hexis to other aspects of self-presentation. Where cool girls aim for either cuteness or sophistication in their personal style, nerd girls aim for silliness. Cool girls play soccer or basketball; nerd girls play badminton. Cool girls read fashion magazines; nerd girls read novels. Cool girls wear tight T-shirts, and either very tight or very baggy jeans; nerd girls wear shirts and jeans that are neither tight nor extremely baggy. Cool girls wear pastels or dark tones; nerd girls wear bright primary colors. But these practices are specific to individuals; they are engaged in by particular nerd girls, not all of them.

The community of practice model accommodates the individuality that is paramount in the nerd social identity, without overlooking the strong community ties that unify the nerd girls in this study. The community of practice also allows us to look at nerd girls in the same way that Eckert \& McConnell-Ginet 1999 view the Burnout girls: as speakers AND social actors, as individuals AND members of communities, and as both resisting and responding to cultural ideologies of gender.

IDENTITY PRACTICES IN A LOCAL NERD COMMUNITY

To illustrate the value of the community of practice framework, I will focus on a single social group that displays the nerd social identity. Nerds at the high school 
in my study constitute a single community insofar as they engage in shared practices, but this identity is divided into particular social groups whose members associate primarily with one another, and these groups form their own communities of practice. In communities of practice, unlike speech communities, the boundaries are determined not externally by linguists, but internally through ethnographically specific social meanings of language use. As suggested above, ethnographic methods therefore become crucial to the investigation of communities of practice.

The ethnographic fieldwork from which the data are taken was carried out during the 1994-95 academic year at a California high school that I call Bay City High. The social group of nerd girls that is the focus of this discussion is a small, cohesive friendship group that comprises four central members - Fred, Bob, Kate, and Loden - and two peripheral members, Carrie and Ada. (Ada does not appear in the data that follow.) All the girls are European American except Ada, who is Asian American. The same group also formed a club, which I will call the Random Reigns Supreme Club. ${ }^{5}$

Random Reigns Supreme is more properly described as an anti-club, which is in keeping with the counter-hegemonic orientation of nerd identity. It was created by members in order to celebrate their own preferences, from Sesame Street to cows to Mr. Salty the pretzel man. Members emphasize the "randomness" of the club's structure. It is not organized around shared preferences; instead, any individual's preferences can be part of the club's de facto charter, and all six members are co-presidents. This structure contrasts with the corporate focus and hierarchical structure of most school clubs, which bring together people who are otherwise unconnected to perform a shared activity (Eckert 1989a). The Random Reigns Supreme Club centers around members' daily practices, not specialized activities. It has no goals, no ongoing projects, and no official meetings. Nevertheless, members proudly take their place among the corporate clubs in the pages of the school's yearbook. The girls' insistence on being photographed for the yearbook has a subversive quality: The photo publicly documents the existence of this otherwise little-recognized friendship group, and demands its institutional legitimacy on par with the French Club, the Backpacking Club, and other activitybased organizations. Like their yearbook photograph, the language used by the girls not only marks their nerd identity but also expresses their separation from outsiders. As shown by the following examples (taken from a single interaction), the details of interaction are important and contested resources in defining a shared oppositional nerd identity within the club's community of practice.

\section{Positive identity practices}

As indicated above, many positive identity practices in which nerds engage contribute to the display of intelligence. The community value placed on intelligence is reflected in non-linguistic identity practices oriented to the world of school, books, and knowledge. This orientation is amply illustrated in the following. ${ }^{6}$ 


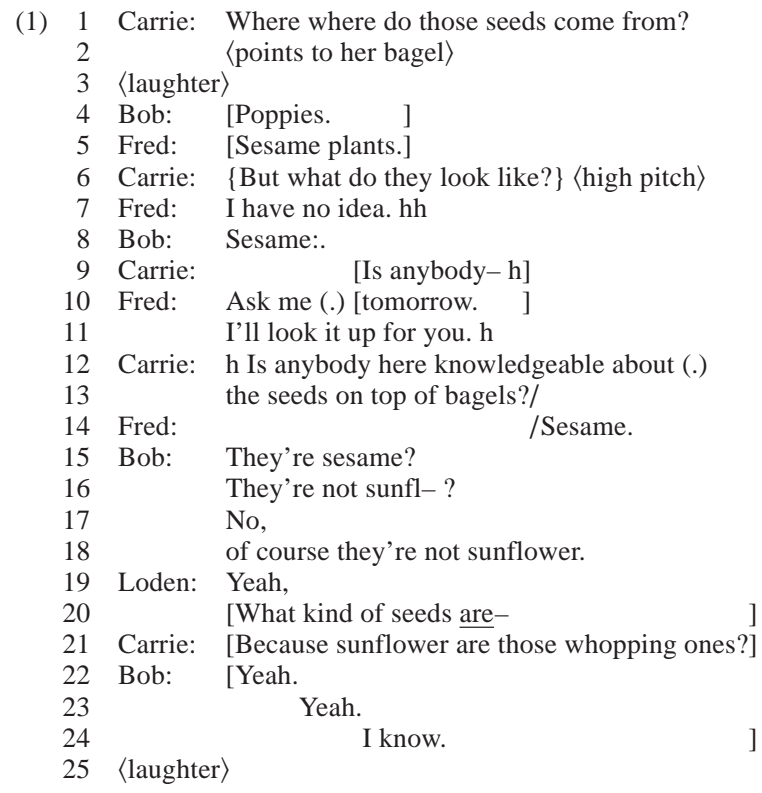

Carrie's question in line 1 creates the conditions for intellectual display. Although the humor of the question is acknowledged through laughter (line 2), it receives immediate, serious uptake from two participants, Bob and Fred (lines 4-5). Carrie's subsequent question (line 6), however, forces an admission of ignorance from Fred (line 7).

Because knowledge is symbolic capital within the nerd community of practice, Fred's admission results in some loss of face. She recovers from this (minor) social setback by invoking the authority of a reference book (I'll look it up for you, line 11). In this way Fred can safely assure her interlocutor that, although she does not yet know the answer, she soon will. She is also able to one-up Bob, who has misidentified the bagel seeds (line 4) and continues to show some skepticism about Fred's classification of them (Sesame:, line 8). Fred tracks this indirect challenge for five lines, through her own turn and Carrie's next question; rather than continuing to participate in the series of adjacency pairs that Carrie has initiated (lines 12-13), she responds to Bob (line 14). Fred thus succeeds in displaying both actual knowledge, about the type of seeds under discussion, and potential knowledge, about the appearance of sesame plants.

Claims to knowledge are, however, often disputed in this community of practice. After Bob provides an incorrect answer to Carrie and receives a correction from Fred, she continues to exhibit doubt about Fred's knowledge (line 15). She offers a second incorrect identification of the seeds in line 16, but this time she interrupts herself and self-corrects (lines 17-18), in an effort to prevent further other-correction. She does not succeed, however; and when Carrie explains why 
Bob is mistaken, the latter overlaps with her, offering three quick acknowledgments that are designed to cut off Carrie's turn (lines 22-24).

This passage shows several deviations from the preference organization of repair in conversation (Schegloff et al. 1977), according to which self-initiation and self-repair are preferred over initiation and repair by another. Bob twice initiates dispreferred repairs of Fred's turns (lines 8, 15), and she even begins to carry out the repair itself in line 16 . When Bob initiates a repair of her own utterance through self-interruption in the same line, Carrie performs the repair despite Bob's efforts to prevent her from doing so (lines 21-24). The frequent apparent violations of repair organization suggest that, in this community of practice, self-repair is preferred only by the speaker; the listener's positive face (the desire to be viewed as intelligent) wars against and often overrides consideration of the speaker's negative face (the desire not to be viewed as unintelligent).

Bob's loss of face in ex. 1 leads her, in ex. 2, to initiate a new conversational direction:

(2) 26 Bob: They come from trees.

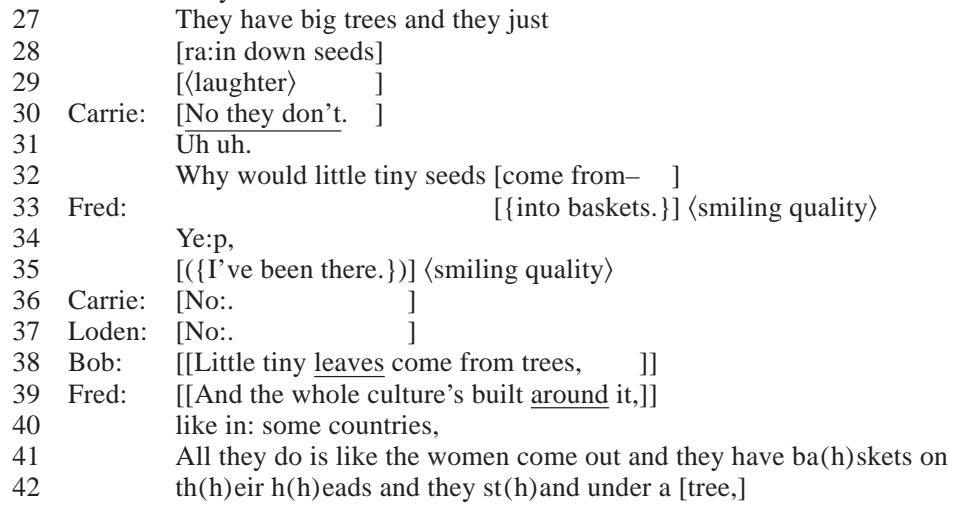

Bob jokingly provides an authoritative answer to Carrie's question (lines 26-28) and thereby skillfully shifts attention from her own lack of knowledge to Carrie's. Fred eagerly joins in with the parody of scientific discourse, amplifying on the theme while supplying invented anthropological details that invoke the didactic style of a typical high-school classroom or public television documentary (33$35,39-42)$. Such teasing episodes are frequent in this friendship group. But more importantly, this exchange is a collaborative performance of nerd identity: The participants collude in sustaining the frame of an intellectual debate, even as laughter keys the talk as play. Nerd identities are here jointly constructed and displayed.

In ex. 3, Carrie - who up to this point has mostly provided opportunities for others to display their nerd identities, rather than participating herself (but see below) - shifts the topic, which she sustains for the rest of the interaction: 


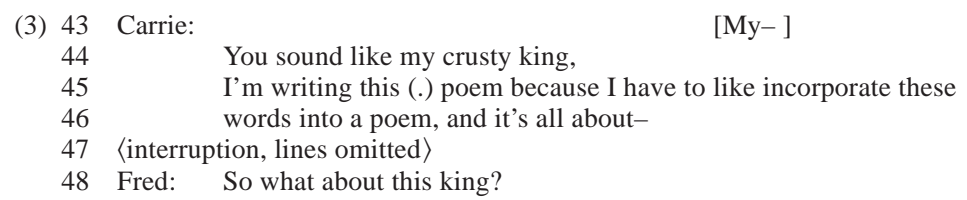

Carrie's discussion of a class assignment returns to a central value of nerdiness: school. The topic is sustained for 56 lines and 26 turns; and although it is interrupted immediately after Carrie introduces it (line 47), Fred prompts her to return to the subject several minutes later (line 48). Carrie's enthusiastic description of her poem - and the eager participation of others in this topic - is rare among students with cool social identities, but it is quite common among nerds, for whom academic pursuits are a central resource for identity practices.

At the same time, however, Carrie's selection of subject matter for her poem, with its mildly scatological - or at least "gross" theme (line 80) - is playfully subversive of school values and emphatically counter to traditional feminine topics, as ex. 4 illustrates:

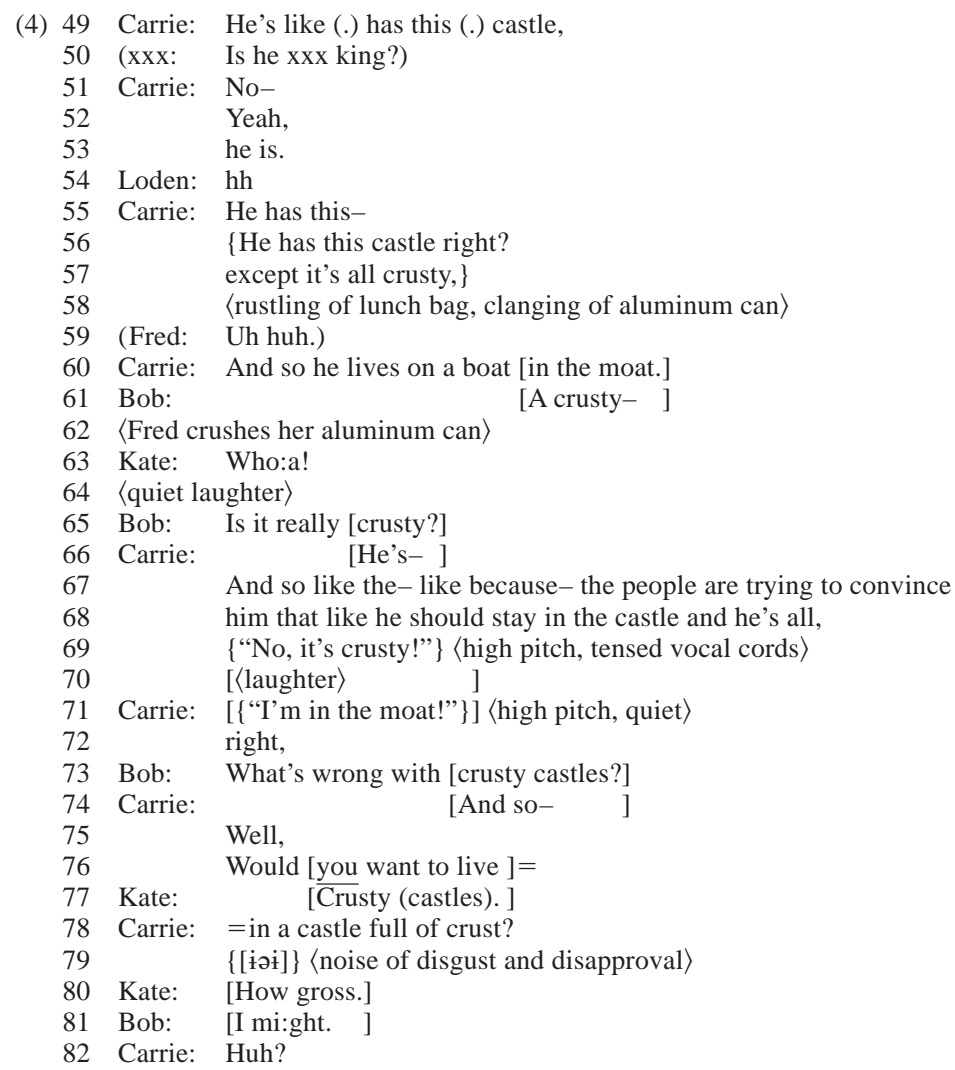


Bob here enters into the unfeminine spirit of Carrie's narrative, even outdoing Carrie with her repeated insistence on her own immunity from "gross" subjects like crustiness (lines 73, 81). A competitive tone is also evident in the multiple challenges she issues to Carrie throughout the latter's narrative (lines 65, 73). As questions, these challenges echo Carrie's earlier questions (lines 1, 6, 12-13); but whereas Carrie's appeared to be genuine information-seeking questions, Bob's are not. Carrie's recognition of this fact is shown by her failure to respond at all to the first question, and by her answering the second question with an equally challenging question of her own (Would you want to live in a castle full of crust?, lines 76, 78). Bob's face-threatening response ( $\mathrm{mi}$ : ght, line 81 ) perpetuates the jocular-combative tone. In ex. 5, however, this combativeness becomes not a shared resource for joint identity construction, but a marker of social division. The positive identity practices that dominate in the earlier part of the interaction are replaced by negative identity practices, as community members experience a threat not only to their face but also to their identities.

\section{Negative identity practices}

Example 5 is a continuation of Bob's face-threatening questions to Carrie. This final series of questions is unified through a shared template (like $+\mathrm{ADJ}+$ crust); their syntactic similarity emphasizes that they are designed as a series, and it thus produces an effect of unremitting interrogation.

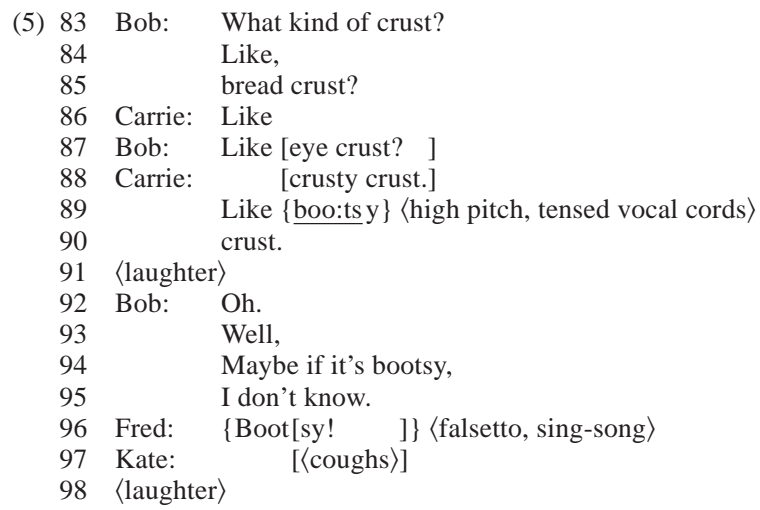

These questions display Bob's nerd identity through her use of puns on the word crust (lines 85, 87). Punning, as a discourse practice that orients to linguistic form, is characteristic of nerds' discourse style (see Table 1). Carrie's refusal (line 88) to participate in Bob's punning thus constitutes a negative identity practice one which, moreover, indexes a rejection of nerd identity as it has been constructed through preceding interactional practices. The refusal is made more evident by her exploitation (lines 86, 88-90) of Bob's syntactic template. By conforming to the syntactic form of Bob's turn, while failing to conform to the 
discourse practice of punning, Carrie separates herself from Bob at a point when the latter is fully engaged in nerdy identity practices.

This analysis is confirmed by Carrie's choice of upgraded adjective in line 89. Bootsy is a slang term with a negative evaluative sense; it is not used by other members of the Random Reigns Supreme Club. The introduction of youth slang into a group that explicitly rejects such linguistic forms is part of a strongly negative identity practice, and the reactions of Carrie's interlocutors are correspondingly negative: Bob's response (lines 92-95) jokingly concedes the point, while underscoring that Carrie has violated the rules of nerdy argument by appealing to the authority of cool youth culture. Fred's mocking repetition of the term (line 96) demonstrates that the use of slang is itself worthy of comment. With Carrie's narrative entirely derailed - it never becomes clear how it is connected to the earlier discussion - she soon afterward moves away from the group.

The complex interaction presented above reveals Carrie's peripheral status in this community of practice. As a non-core member, she moves between friendship groups - in fact, the interaction occurred when Carrie approached the core group in the middle of lunch period. Carrie's social flexibility has made her a cultural and linguistic broker for the Random Reigns Supreme Club, whose members become aware of current youth slang in large part through contact with her. Hence many slang terms that circulate widely in the "cool" groups are labeled by club members as "Carrie words".

Yet Carrie also demonstrates her ability and willingness to participate in the group's positive identity practices. She does so most obviously by engaging in sound play in recounting her poem (crusty king, line 44; a boat in the moat, line 60). More significant, though, is the subtle shift in her speech practices at the beginning of the interaction. Thus Carrie's question Is anybody here knowledgeable about (.) the seeds on top of bagels? (lines 12-13) draws on the formal register through her choice of the word knowledgeable. Among nerds, this register projects a speaker's persona as smart and highly educated. But the use of the formal register is strategic, not a mechanical result of membership in a particular social category. This point is supported by the fact that Carrie employs the nerd identity practice only after she asks two related questions in colloquial register (lines 1, 6). Her unwillingness to overlap her turn with Fred's (lines 9, 10) further suggests that the question is a performance of nerdiness, not just a manifestation of it; she does not produce her utterance until she is assured of an attentive audience. That is, Carrie is simultaneously displaying and commenting on nerd practice - showing her awareness of nerdy linguistic forms, and announcing her willingness to enter a nerdy interactional space by carefully gauging her utterance to match the group's practices. Thus Carrie's performance of nerdiness places her within the community of practice; but her use of slang, as the other members are quick to let her know, moves her outside it. Such adjustments at interactional boundaries may reflect adjustments at community boundaries. 
C O N C L US I O N

Because all the participants in the above exchange are middle-class European American girls from the same California city, the traditional sociolinguistic perspective would classify them unproblematically as members of the same speech community. Such an analysis would overlook the details of greatest interest to language and gender researchers: the performances of identity, and the struggles over it, which are achieved through language. However, by viewing the interaction as the product of a community of practice, we can avoid this problem, as well as others associated with the speech community model.

The ethnographic method brings into view the social meanings with which participants invest their practices. These meanings emerge on the ground in local contexts; thus what it means to display academic knowledge, or to use slang, depends not on fixed identity categories but on where one is standing. Nor do participants necessarily agree on the meanings of their actions; nerdiness, like all identities, is a contested domain in which speakers struggle both over control of shared values, via positive identity practices (Who's better at being a nerd?), and over control of identity itself, via negative identity practices (Who counts as a nerd?). Such conflicts reveal the heterogeneity of membership in the community of practice - its constitution through the work of central and peripheral members alike. In this project, the interactional choices of specific individuals matter. Thus Carrie's identity is on display - and at risk - in a way that Loden's, for example, is not. These actions must be seen as choices, not as the outputs of interactional algorithms. While some practices reproduce the existing local social structure (as does Carrie's use of the formal register), others undermine it (e.g. her use of slang). Likewise, some nerdy practices (such as being good students) comply with the larger social order, while others (such as rejecting femininity) resist it. Linguistic practices, moreover, have no special status in this process. Instead, they work in conjunction with other social practices to produce meanings and identities. Bob's interactional work to distance herself from hegemonic femininity, for instance, is part of her overall participation in anti-feminine practices and her non-participation in feminine practices, as evidenced also by her physical self-presentation.

For sociolinguists, the community of practice represents an improvement over the speech community in that it addresses itself to both the social and the linguistic aspects of the discipline. As a well-grounded framework with currency in a number of fields, practice theory in general, in particular the community of practice, revitalizes social theory within sociolinguistics. What is more, it does so at a sufficiently general level to accommodate multiple dimensions of social analysis - including both structure and agency, both ideology and identity, both norms and interactions. The community of practice also provides an avenue for a more complete sociolinguistic investigation of identity. Although introduced for genderbased research, the community of practice has never been restricted to the analysis of a single element of identity. Indeed, it lends itself to the simultaneous 
investigation of multiple aspects of the self, from those at the macro level - like gender, ethnicity, and class - to micro-identities like Jocks, Burnouts, or nerds. The framework also allows for the study of interaction between levels of identity. The concepts of positive and negative identity practices, as proposed in this article, are intended as one way to develop the potential of the community of practice in this arena.

In addition to its benefits for social analysis, the community of practice offers an integrated approach to linguistic analysis. By understanding all socially meaningful language use as practices tied to various communities, the model enables researchers to provide more complete linguistic descriptions - along with social explanations - of particular social groups. Moreover, the community of practice provides a way to bring qualitative and quantitative research closer together. Because both kinds of linguistic data emerge from practice, both can be included in a single analysis. This richly contextualized approach to both language and society is one of the great strengths of the community of practice as a sociolinguistic framework.

The community of practice, having revolutionized the field of language and gender almost as soon as it was first proposed, enables researchers of socially situated language use to view language within the context of social practice. Perhaps the most valuable feature is that the community of practice admits a range of social and linguistic phenomena that are not analyzed in other theoretical models. Local identities, and the linguistic practices that produce them, become visible to sociolinguistic analysis as the purposeful choices of agentive individuals, operating within (and alongside and outside) the constraints of the social structure. To describe and explain such complexity must be the next step not only for language and gender scholars, but for all sociolinguists concerned with the linguistic construction of the social world.

\section{NOTES}

* My thanks to Janet Holmes, Chris Holcomb, Stephanie Stanbro, and members of the Ethnography/ Theory Group at Texas A\&M University for comments on and discussion of the ideas in this article.

${ }^{1}$ The work of Barbara Horvath on immigrants in Sydney's speech community (Horvath 1985, Horvath \& Sankoff 1987) has done a great deal to correct this omission.

${ }^{2}$ Santa Ana \& Parodi's model of nested speech communities (1998) is a recent attempt to address this problem.

${ }^{3}$ A fuller discussion of the advantages of practice theory for language and gender research is provided by Bucholtz 1999.

${ }^{4}$ Eckert 1989b calls this simple formulation into question; see also Labov 1990 for a response.

${ }^{5}$ Though this is not its actual name, it preserves the flavor of the original. All other names are pseudonyms chosen by the speakers.

${ }^{6}$ Transcription conventions are as follows:

$\begin{array}{ll}\cdot & \text { end of intonation unit; falling intonation } \\ , & \text { end of intonation unit; fall-rise intonation } \\ - & \text { end of intonation unit; rising intonation } \\ - & \text { self-interruption } \\ & \text { length }\end{array}$




\section{MARY BUCHOLTZ}

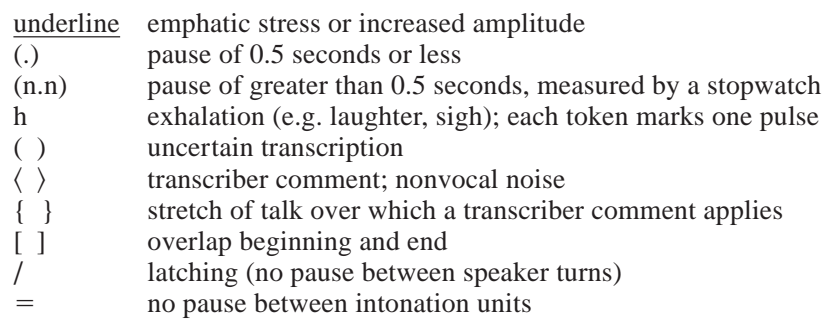

The transcript emphasizes sequential organization in order to highlight speakers' orientation to one another. It excludes phonological detail that is necessary for a complete analysis of nerd identity performance.

\section{R EFERENCES}

Bloomfield, Leonard (1933). Language. New York: Holt.

Bourdieu, Pierre (1978). Outline of a theory of practice. Cambridge \& New York: Cambridge University Press. (1991). Language and symbolic power. Cambridge, MA: Harvard University Press.

Bucholtz, Mary (1998). Geek the girl: Language, femininity, and female nerds. In Natasha Warner et al. (eds.), Gender and belief systems: Proceedings of the Fourth Berkeley Women and Language Conference, 119-31. Berkeley: Berkeley Women and Language Group. (1999). Bad examples: Transgression and progress in language and gender research. In Mary Bucholtz et al. (eds.), Reinventing identities. To appear, New York: Oxford University Press.

Cameron, Deborah (1992). Feminism and linguistic theory. 2d edn. New York: St. Martin's Press.

Chambers, J. K. (1995). Sociolinguistic theory. Oxford: Blackwell.

Certeau, Michel de (1984). The practice of everyday life. Berkeley: University of California Press.

Dorian, Nancy C. (1982). Defining the speech community to include its working margins. In Suzanne Romaine (ed.), Sociolinguistic variation in speech communities, 25-33. London: Arnold.

Eckert, Penelope (1989a). Jocks and Burnouts: Social categories and identity in the high school. New York: Teachers College Press.

(1989b). The whole woman: Sex and gender differences in variation. Language Variation and Change 1:245-67.

\& McConnell-Ginet, Sally (1992). Think practically and look locally: Language and gender as community-based practice. Annual Review of Anthropology 21:461-90.

(1995). Constructing meaning, constructing selves: Snapshots of language, gender, and class from Belten High. In Kira Hall \& Mary Bucholtz (eds.), Gender articulated: Language and the socially constructed self, 459-507. London: Routledge.

Giddens, Anthony (1979). Central problems in social theory: Action, structure, and contradiction in social analysis. Berkeley: University of California Press.

Guy, Gregory R. (1988). Language and social class. In Frederick J. Newmeyer (ed.), Linguistics: The Cambridge survey, vol. 4: Language: The socio-cultural context, 37-63. Cambridge \& New York: Cambridge University Press. 37-63.

Hinton, Leanne, et al. (1987). It's not just the Valley Girls: A study of California English. Berkeley Linguistics Society 13:117-28.

Holmes, Janet (1997). Women, language and identity. Journal of Sociolinguistics 1:195-223.

Horvath, Barbara (1985). Variation in Australian English: The sociolects of Sydney. Cambridge \& New York: Cambridge University Press.

\& Sankoff, David (1987). Delimiting the Sydney speech community. Language in Society 16:179-204.

Hudson, Richard A. (1980). Sociolinguistics. Cambridge \& New York: Cambridge University Press.

Hymes, Dell (1974). Foundations in sociolinguistics: An ethnographic approach. Philadelphia: University of Pennsylvania Press.

Johnstone, Barbara (1995). Sociolinguistic resources, individual identities, and public speech styles of Texas women. Journal of Linguistic Anthropology 5:183-202. 
(1996). The linguistic individual: Self-expression in language and linguistics. Oxford \& New York: Oxford University Press.

\& Bean, Judith Mattson (1997). Self-expression and linguistic variation. Language in Society 26:221-46.

Kinney, David A. (1993). From nerds to normals: The recovery of identity among adolescents from middle school to high school. Sociology of Education 66:1.21-40.

Labov, William (1966). The social stratification of English in New York City. Washington, DC: Center for Applied Linguistics.

(1972). The reflection of social processes in linguistic structures. In his Sociolinguistic patterns, 110-21. Philadelphia: University of Pennsylvania Press.

(1990). The intersection of sex and social class in the course of linguistic change. Language Variation and Change 2:205-54.

Lave, Jean (1988). Cognition in practice: Mind, mathematics, and culture in everyday life. Cambridge \& New York: Cambridge University Press.

, \& Wenger, Etienne (1991). Situated learning: Legitimate peripheral participation. Cambridge \& New York: Cambridge University Press.

Luthin, Herbert W. (1987). The story of California (ow): The coming-of-age of English in California. In Keith M. Denning et al. (eds.), Variation in language: NWAV-XV at Stanford, 312-24. Stanford, CA: Department of Linguistics, Stanford University.

Milroy, James (1992). Linguistic variation and change: On the historical sociolinguistics of English. Oxford: Blackwell.

Morgan, Marcyliena (1999). No woman, no cry: Claiming African American women's place. In Mary Bucholtz et al. (eds.), Reinventing identities (to appear).

Ortner, Sherry (1996). Making gender: The politics and erotics of culture. Boston: Beacon.

Pratt, Mary Louise (1987). Linguistic utopias. In Nigel Fabb et al. (eds.), The linguistics of writing: Arguments between language and literature, 48-66. New York: Methuen.

Rickford, John R. (1986). The need for new approaches to social class analysis in sociolinguistics. Language and Communication 6:3.215-21.

Romaine, Suzanne (1982). What is a speech community? In Suzanne Romaine (ed.), Sociolinguistic variation in speech communities, 13-24. London: Arnold.

Santa Ana, Otto, \& Parodi, Claudia (1998). Modeling the speech community: Configuration and variable types in the Mexican Spanish setting. Language in Society 27:23-51.

Schegloff, Emanuel; Jefferson, Gail; \& Sacks, Harvey (1977). The preference for self-correction in the organization of repair in conversation. Language 53:361-82.

Silverstein, Michael (1996). Encountering languages and languages of encounter in North American ethnohistory. Journal of Linguistic Anthropology 6:126-44.

Tolone, W. L., \& C. R. Tieman (1990). Drugs, delinquency and nerds: Are loners deviant? Journal of Drug Education 20:2.153-62.

Wenger, Etienne (1998). Communities of practice. Cambridge \& New York: Cambridge University Press.

Williams, Glyn (1992). Sociolinguistics: A sociological critique. London: Routledge. 